\title{
Are Agatha, Dashiell, and Arthur alive? Assessing the links between hand movements and false intentions
}

\author{
Tomás Sanches de Baêna ${ }^{1}$ \\ ${ }^{1}$ Centre for Research on Criminal Law and Criminal Sciences (CIDPCC), School of Law, University of \\ Lisbon
}

Corresponding author: Tomás Sanches de Baêna | tomas.baena@gmail.com

Received:

17 September 2019

Last revised:

01 September 2020

Accepted:

03 September 2020

\begin{abstract}
Background: With the ever-increasing political, ideological and social tension which followed $9 / 11$, crime prevention stands as an issue of major relevance. The development of the ability to accurately detect statements of false intent is of great societal and legal value. It could aid intelligence services in preventing crimes (e.g., terrorist threats) and security services in reinforcing their protocols (e.g., airport security checks, parole hearings, and border control).

Goals: To examine the associations between hand movements and false intentions in adults.

Methods: Using a laboratory-based variation of the 'Portsmouth design', 23 students completed a questionnaire about their intentions to travel in the near future. Participants with a planned trip were placed in the truth tellers' condition $(n=12)$. Those who did not have a planned trip were placed in the liars' condition $(n=11)$. Based on the main theoretical approaches, three hypotheses were proposed. Hypothesis 1 advocated a decrease in the three categories of illustrators (movements interconnected to speech that serve to illustrate what is being verbally said) in liars, as compared to the truth tellers. Hypothesis 2 also suggested a decrease in the category of subtle hand and finger movements in the lying condition, comparatively with the truth condition. Finally, hypothesis 3 proposed a lack of significant differences between liars and truth-tellers in the five categories of self-adaptors (movements in which one part of the body does something to another body part, such as scratching the ear or squeezing the hands).

Results: Hypothesis 1 was partially supported. The general and the unilateral categories of illustrators decreased in the case of the liars, as compared to the truth tellers; however, the bilateral category of illustrators slightly increased in the lying condition, in comparison with truth telling. Hypotheses 2 and 3 were fully supported.

Discussion: Apart from the slight increase of bilateral illustrators in the case of the liars, all the results are in accordance with the empirical findings on deception research about past events. This similarity is noteworthy, considering the cognitive differences between lies about past events and lies about future events.
\end{abstract}

Keywords: Hand movements, Intention, Deception, Cognitive load.

\section{Introduction}

Agatha (Christie), Dashiell (Hammett), and Arthur (Conan Doyle) are the three psychics in Steven Spielberg's science fiction movie Minority Report. They are able to foresee criminals' intentions and allow the "Precrime Police Unit" to capture suspects before they perpetrate criminal acts. The movie was inspired by a Philip K. Dick's dystopic short story published in 1956. Although we are very far from this futuristic scenario, the relationship between intentions and deception in a psycho-legal setting has been systematically studied since the publication of Granhag's (2010) pivotal work. Since then, more than twenty experimental studies have been published (for a review, see Mac Giolla, 2016).

Apart from one study included in a PhD dissertation (Warmelink, 2012), the link between non-verbal behaviour and false verbalized intentions has not yet been assessed in detail. We addressed this gap in the literature by developing a study within a psycho-legal 
framework that links experimental psychology (Myers \& Hansen, 2012), deception detection about intentionality (Vrij, Granhag, Mann, \& Leal, 2011a), and hand movement analysis (Ekman \& Friesen, 1972). The improvement of the aptitude to correctly identify statements of false intent is of great social and legal value. It could support intelligence services in preventing crimes (e.g., terrorist threats) and security services in strengthening their protocols (e.g., airport security checks, parole hearings, and border control).

\section{Hand Movements and False Intentions}

Some research proposes that imagining the future depends on the same cognitive and neurophysiological processes that are employed to remember the past (Schacter \& Addis, 2007; Schacter, Addis, \& Buckner, 2008). In other words, both the ability to imagine the future and to remember the past rely on episodic memory (Szpunar, 2010). Even though images of past events appear to be clearer and more detailed than images of future events ( $D^{\prime}$ Argembeau \& Van der Linden, 2004; Gamboz, Brandimonte, \& De Vito, 2010), Warmelink, Vrij, Mann, \& Granhag (2013) propose that they may be analysed and evaluated in a similar way. As a logical correlate, "lie detection methods used to detect lies in statements about past events may also work to detect lies in statements about future events" (Warmelink et al., 2013, p. 101).

Drawing on this premise, the main theoretical support for the current study is the 'multi-factor' model (Zuckerman, DePaulo, \& Rosenthal, 1981), one of the most influential approaches on non-verbal cues to deception about past events (Vrij, 2014). Thus, the present study compares the differences between illustrators, self-adaptors, and subtle hand and finger movements, the three leading categories of hand movements used in deception research (DePaulo, Lindsay, Malone, Muhlenbruck, Charlton, \& Cooper, 2003; Vrij, 2008), in both truthful and false statements about future intentions.

Ekman and Friesen (1969a, p. 68) defined illustrators as "movements directly tied to speech, serving to illustrate what is being said verbally". Illustrators can only occur with speech and are interconnected with the content of the speech they are accompanying (Krauss,
Chen, \& Chawla, 1996). On the other hand, self-adaptors can be defined as "movements in which one part of the body does something to another body part. Scratching the head, picking the nose, wringing the hands [...] are examples" (Ekman, 1977, p. 47). They provide sensory stimulation to relieve stress and emotional arousal and satisfy self or bodily needs (Ekman \& Friesen 1969b, 1974). Finally, subtle hand and finger are non-functional movements which "differ somewhat from illustrators or adaptors" (Vrij, Akehurst, \& Morris, 1997, p. 93) as they do not include arm movements. Consequently, all hand and finger movements that do not include arm movement, as well as rubbing one's hands and fidgeting, are classified as 'subtle hand and finger movements' (Vrij, 1993, 1994, 1995).

The cognitive load and the attempted behaviour control factors from predict that liars generate fewer illustrators and subtle hand and finger movements than truth tellers (Zuckerman et al., 1981). Therefore, hypothesis 1 suggested that liars would make fewer illustrators than truth tellers, and hypothesis 2 proposed that liars would make fewer subtle hand and finger movements than truth tellers. On the other hand, the general arousal and the emotional reaction factors, which predict an increase in self-adaptors, were not expected to be present in a laboratory-based study with low-stake lies. For that reason, hypothesis 3 advocated that there would be no significant difference in self-adaptors between liars and truth tellers.

\section{Methods}

\section{Experimental Design}

The experimental design selected for the present study is described in Experiment 1 by Warmelink et al. (2013; see also Warmelink, Vrij, Mann, Jundi, \& Granhag, 2012), which is a variation of the 'Portsmouth design' (Granhag \& Mac Giolla, 2014; Jupe, Leal, Vrij, \& Nahari, 2017; Mann, Vrij, Leal, Granhag, Warmelink, \& Forrester, 2012; Mann, Vrij, Nasholm, Warmelink, Leal, \& Forrester, 2012, Experiment 1; Vrij et al., 2011a; Warmelink, 2012; Warmelink, Vrij, Mann, Leal, Forrester, \& Fisher, 2011; Warmelink et al., 2013, Experiment 2) developed for a laboratory- 
based setting. It is important to note that all these studies, as well as the present study, used a restricted definition of intention, namely a single act that is planned to be performed in the near future (Granhag, 2010).

The independent variable was veracity, specifically a between-subject variable comprising truth tellers or liars. One group answered all questions truthfully (truth tellers), and the other group answered all questions deceptively (liars). The dependent variables were illustrators, self-adaptors, and subtle hand and finger movements. Illustrators were divided in terms of general frequency and laterality frequency (unilateral or bilateral), and self-adaptors were divided into general frequency, laterality frequency (unilateral or bilateral), and length frequency (brief or long). Subtle hand and finger movements were examined in terms of general frequency. Consequently, the three main variables were segmented into nine categories:

Illustrators:

- Unilateral frequency

- Bilateral frequency

- General frequency

Self-adaptors:

- Unilateral frequency

- Bilateral frequency

- Brief frequency

- Long frequency

- General frequency

Subtle hand and finger movements:

- General frequency

\section{Participants}

The sample comprised a total of 23 participants (8 males and 15 females), and their average age was $M=40.86$ ( $S D=7.48)$. They were all students from a Portuguese training institute that delivers personal development courses. All written instructions were translated from English to Portuguese from the original protocol (see Warmelink et al., 2013, Experiment 1). To ensure the rigour of the translation, a licensed translator was responsible for this process.

\section{Procedure}

Participants completed a paper-based questionnaire about their travel plans. These data were used to allocate participants to the conditions (truth tellers or liars). The questionnaire asked whether the participant planned to travel in the near future. If they had plans, they were asked where, when and why they were going to travel. Participants were also requested to list all countries and major cities they had visited in the past five years. Participants with a planned trip were placed in the truth tellers' condition. Those who did not have a planned trip were placed in the liars' condition. Participants only knew their conditions on the day of the interview.

\section{Pre-interview stage}

The research was conducted in two separate rooms at the Institute. On the day of the interview, we accompanied each participant to the first room and explained that the interviewer was going to ask him/her some questions about his/her future intention to travel. Following Warmelink et al. (2013, p. 102) design, participants allocated to the truth teller's condition were given the following instructions:

\begin{abstract}
"In the interview I want you to answer the questions truthfully. Some people are asked to lie during the interview. The interviewer knows that some people may lie but does not know whether you are telling the truth or lying. Your goal is to convince the interviewer that you really are telling the truth." (Warmelink et al., 2013, p. 102-103)
\end{abstract}

If the participant was allocated to the liars' condition, he/she received the subsequent instruction:

"In the interview I want you to lie and pretend that you are travelling to [matched destination] and that you are going there for the purpose of [matched reason]. The interviewer knows that some people may lie but does not know whether you are lying or telling the truth. Your goal is to convince the interviewer that you are telling the truth." (Warmelink et al., 2013, p. 102103) 
Liars were given a false destination and a false reason for their trip a few minutes before the interview. Participants were asked if they needed preparation time for the interview. However, nobody requested preparation time. When the liars were given their false destination, they were asked to confirm they had never been to that city. False destinations and false reasons agreed with the destinations and reasons described by the truth tellers. This matching avoided a variance in the travel destination and the reasons for travel between the truth tellers and the liars (Warmelink et al., 2013, p. 102). To illustrate, one participant from the current study genuinely intended to travel to Oslo in April to attend a business meeting. This information was given to one of the liars, ensuring that he had not been to Oslo for at least five years. Interestingly, none of the liars had ever been to any of the assigned cities. The study only continued after ensuring that the participant clearly understood all the instructions, and the option to have preparation time for the interview had been given.

\section{Interview stage}

When the participant was ready, $\mathrm{s} / \mathrm{he}$ was taken to the second room, where the female interviewer was waiting. The interviewer was a Clinical Psychologist, PhD student, from the University of Lisbon who agreed to participate in the study. She did not work for the institute and was blind to participants' conditions. The participant sat in a chair in front of her. A camera was placed three meters away from the participant, in order to record his/her entire body. The interviewer started the interview by posing the preset questions. The interview questions from Warmelink's (2012) study could not be used because "the complete list of questions is confidential for security reasons and we are not allowed to publish it in full" (Warmelink, 2012, p. 32).

Instead, a sample of the twenty-six questions from Warmelink et al. (2013) study were used. Ten questions were selected for practical reasons, namely, to ensure that the independent collaborators had time to code all the hand movements from the twenty-three interviews (see Table 1). Warmelink et al. (2013) questions were divided into four categories: general, core event, transportation, and planning. The first two questions were chosen from each category. There was one exception, however, in the core event category, where three questions were added because one question simply required a "yes" or "no" answer. In addition, a final question was included ("Do you want to add anything?"), which was repeated at the end of each category, in the original script. The questioning sequence followed Warmelink et al. (2013) study.

Table 1. Questioning sequence for the interview

\begin{tabular}{l}
\hline Anticipated general questions \\
\hline Where are you travelling to? \\
What is the main purpose of your trip? \\
\hline Core event questions \\
\hline What is the most important place you'll go to on your trip? \\
Do you have a mental picture of this? Yes or no? \\
In your picture, where are you? \\
\hline Transportation questions \\
\hline How are you going to travel to your destination? \\
How long will the journey take? \\
\hline Planning questions \\
\hline Please tell me in as much detail as possible what you have to \\
do to plan this trip? \\
Please tell me in which order you did the planning. What \\
first, what second, what last? \\
\hline Additional comments questions \\
\hline Do you want to add anything?
\end{tabular}

\section{Post-interview stage}

After the interview, participants were taken back to the first room. Participants were asked what they thought the study was about. Some participants said that the study could be related to eye movements or verbal statements, but none connected the study with hand movements.

\section{Hand movement coding system}

The coding system chosen for this study was the "Hand Movement Code" developed by Friesen and Ekman in 1973 (see also Ekman \& Friesen, 1972, 1974), and later revised by Friesen, Ekman and Wallbott (1979). The frequency of all observable movements, from the initial reaction of the interviewee to the first question to his/her final answer, was analysed. The frequency of every single illustrator was scored. Bilateral illustrators were scored as one movement. 
Following the coding procedures, the laterality frequency (unilateral and bilateral) was also scored. Hence, illustrators were scored according to three criteria: unilateral, bilateral and general frequency. As with illustrators, the laterality frequency (unilateral and bilateral) and the general frequency of self-adaptors were scored. Friesen et al. (1979, p. 100) also included self-adaptors' length in the coding procedures (see also Freedman, Blass, Rifkin, \& Quitkin, 1973; Mintzlaff, Carney, \& Harrigan, 1999). A distinction was made between brief (less than 2 seconds) and long (more than 2 seconds) self-adaptors. Consequently, self-adaptors were coded according to five criteria: unilateral, bilateral, brief, long, and general frequency.

A third variable, not mentioned in the "Hand Movement Code", was included in the study, namely the subtle hand and finger movements (Vrij, 1993, 1994, 1995). Although the directives to code these movements were not included in the "Hand Movement Code", we closely followed the detailed instructions provided by Vrij (1995; Vrij, Semin, \& Bull, 1996; Vrij et al., 1997; Vrij, Edward, Roberts, \& Bull, 2000). The frequency of all subtle hand and finger movement was coded. Concurrent movements of several fingers were scored as a single movement. Continuing movements, including rubbing one's hands together and fidgeting, were scored every two seconds (Vrij et al., 1997). Since Vrij (1995) does not reference laterality or length in the scoring procedures, subtle hand and finger movements were only coded according to the general frequency criterion.

The study used three independent collaborators trained in the "Hand Movement Code", which independently coded the twenty-three recorded interviews. They had access to a computer with the data but were blind to participants' conditions. Following Friesen et al. recommendation (1979, p. 99), all recordings had the sound removed so that the collaborators were not influenced by the verbal statements. The Intraclass Coefficient Correlation (ICC) was used to analyse the reliability among the three independent coders. Results indicated a highly significant reliability among the three coders (illustrators ICC $=.997$; subtle hand and finger movements $I C C=.995$; self-adaptors ICC $=.959)$.

\section{Ethical issues}

The study was approved by the Academic Ethics Committee of Manchester Metropolitan University. The director of the training institute gave written permission for inviting students for the research, as well as permission to use the institute's facilities. The independent collaborators, responsible for the coding process, signed an agreement form to ensure data confidentiality.

Students were invited to participate in the study during a class break. All students received the participant information sheet, which described the main implications and study procedures. The information sheet also indicated that, if they agreed to participate, they would complete a questionnaire that same day and take part in an interview, after classes, on the following day. Those who agreed with all the procedures were presented with a consent form to read and complete. Those who declined did so because they could not stay after classes to take part in the interview. Before leaving the room, all participants received a chocolate bar with the word "Obrigado" ("Thank you" in English) stamped, as a gift for contributing to the study.

\section{Results}

The MANOVA test examined whether there was an association among the nine hand movement categories per experimental condition. The test did not detect a statistically significant effect of the experimental conditions on hand movements $\left(F_{(8,14)}=0.421, p=.890\right)$.

Therefore, individual ANOVA scores were examined for each variable. Table 2 shows the mean scores, the standard deviations and the ANOVA scores ( $F$ values and $p$-values) for each variable. These results, however, should be analysed with caution due to the small size of the sample $(N=23)$ and the lack of statistical significance for all of the ANOVA scores. 
Hypothesis 1, which relates to liars making fewer illustrators than truth tellers, was partially supported. Unilateral illustrators were less frequent in the case of liars $(M=9.88$; $S D=14.12)$, in comparison with truth tellers $(M=15.20 ; S D=14.92)$. The general frequency of the illustrators also slightly decreased in the case of the liars $(M=26.24 ; S D=31.75)$, as compared to the truth tellers $(M=29.25 ; S D=17.61)$. However, the bilateral illustrators slightly increased during lying ( $M=16.36 ; S D=21.93)$, in comparison with truth telling $(M=14.06 ; S D=9.60)$.

The results supported hypothesis 2, relating to liars making fewer subtle hand and finger movements than truth tellers. These movements were found to be less frequent in liars $(M=15.88 ; S D=13.57)$, as compared to the truth tellers $(M=20.28 ; S D=14.78)$.

Hypothesis 3, which relates to the lack of a significant difference in self-adaptors between liars and truth tellers, was also supported: all the results for selfadaptors revealed minor differences between liars and truth tellers. Additionally, all self-adaptors' categories had considerably lower mean scores, in comparison with illustrators and subtle hand and finger movements. The general frequency of the selfadaptors decreased minimally during lying ( $M=4.18 ; S D=5.66)$, as opposed to truth telling $(M=4.72 ; S D=6.28)$. Unilateral self-adaptors also minimally decreased during lying $(M=3.76 ; S D=4.86)$, in comparison with truth telling $(M=4.50 ; S D=6.17)$. Likewise, brief self-adaptors decreased minimally in the case of liars $(M=3.18 ; S D=4.32)$, as opposed to with truth tellers $(M=3.42 ; S D=5.13)$. Long self-adaptors also minimally decreased in liars $(M=1.00 ; S D=1.58)$, when compared to truth tellers $(M=1.31 ; S D=2.62)$. In contrast, bilateral self-adaptors minimally increased during lying $(M=0.42$; $S D=1.41)$, as compared to truth telling $(M=0.22$; $S D=0.77)$.

Table 2. Hand movements as a function of deception

\begin{tabular}{|c|c|c|c|c|c|c|}
\hline & \multicolumn{4}{|c|}{ Condition } & \multirow[b]{3}{*}{$F$} & \multirow[b]{3}{*}{$p$-value } \\
\hline & \multicolumn{2}{|c|}{ Truth } & \multicolumn{2}{|c|}{ Lie } & & \\
\hline & $M$ & SD & $M$ & SD & & \\
\hline Subtle hand/finger movements & 20.28 & 14.78 & 15.88 & 13.57 & 0.549 & .467 \\
\hline \multicolumn{7}{|l|}{ Illustrators } \\
\hline Unilateral & 15.20 & 14.92 & 9.88 & 14.12 & 0.767 & 391 \\
\hline Bilateral & 14.06 & 9.60 & 16.36 & 21.93 & 0.110 & .743 \\
\hline general & 29.25 & 17.61 & 26.24 & 31.75 & 0.081 & .779 \\
\hline \multicolumn{7}{|l|}{ Self-adaptors } \\
\hline Unilateral & 4.50 & 6.17 & 3.76 & 4.86 & 0.101 & .754 \\
\hline Bilateral & 0.22 & 0.77 & 0.42 & 1.41 & 0.187 & .670 \\
\hline Brief & 3.42 & 5.13 & 3.18 & 4.32 & 0.014 & .907 \\
\hline Long & 1.31 & 2.62 & 1.00 & 1.58 & 0.112 & .741 \\
\hline General & 4.72 & 6.28 & 4.18 & 5.66 & 0.047 & .831 \\
\hline
\end{tabular}

\section{Discussion}

\section{Hypothesis 1: Liars will make fewer illustrators than truth tellers}

Since this study was laying empirical findings for a new area of research, it was important to detail the data as much as possible. For that reason, the complete instructions in the "Hand Movement Code" (Ekman
\& Friesen, 1972, 1974; Friesen \& Ekman, 1973; Friesen et al., 1979) were followed, and were used to code the unilateral, the bilateral and the general frequency of illustrators. Nevertheless, there was no specific hypothesis that linked the laterality of illustrators with deception due to the absence of studies in this area. The majority of research concerning the laterality of illustrators has focused on developmental psychology (e.g., Mumford \& Kita, 2016), evolutionary psychology 
(e.g., Cochet \& Byrne, 2013), brain analysis and hemispheric specialisation (e.g., Mäki-Marttunen, Villarreal, \& Leiguarda, 2014), and pathology (e.g., Foundas, Macauley, Raymer, Maher, Heilman, \& Rothi, 1995). Although Ekman (1985) examined the display of emblematic slips (e.g., the unilateral shoulder shrug) and the asymmetry of facial expressions (Ekman, 2003; Frank \& Ekman, 1993), he did not connect illustrators' laterality with deception. The main goal was to find out if coding the laterality of illustrators would point out to different directions from the general frequency of illustrators.

As described in the results chapter, hypothesis 1 was partially supported. The general frequency of illustrators slightly decreased in liars, when compared with truth tellers. This result is in line with DePaulo et al. (2003) and Vrij's (2008) meta-analyses, which found a slight tendency for illustrators to decrease during deception. The results, however, were different when the unilateral and bilateral illustrators were examined. Unilateral illustrators decreased in liars, in comparison with truth tellers. Although not statistically significant, this was the highest difference among all the variables. In contrast, bilateral illustrators slightly increased during deception, in comparison with truth telling. This last result, though weak, was in contradiction with the multi-factor model (Zuckerman et al., 1981), and both meta-analyses (DePaulo et al., 2003; Vrij, 2008). Therefore, a more detailed analysis of illustrators allowed different results not available by the sole examination of the general frequency of illustrators.

Interestingly, none of the studies described in both meta-analyses examined specific types of illustrators (the only exception was Caso, Maricchiolo, Bonaiuto, Vrij, \& Mann, 2006). Important information may be lost when all the illustrators are coded together as though they represent the same action. Thus, one reason for the weakness of results found for illustrators in deception research (DePaulo et al., 2003; Vrij, 2008) may be the lack of measurement detail (Caso et al., 2006). Even though several authors detail specific types of illustrators, researchers persist in solely coding a general category of illustrators (Hillman, Vrij, \& Mann, 2012).
There were two innovative studies which may shed some light onto this matter. Caso et al. (2006) was the first study to examine different types of illustrators during deceptive and truthful statements about past events. Illustrators as a general category were not linked with deception. Nevertheless, when specific categories of illustrators were examined separately, noteworthy differences emerged. Truth tellers made considerably more deictic illustrators, which are used to indicate concrete objects and people, whereas liars made considerably more metaphoric illustrators, which are used to indicate abstract ideas. Following Caso et al. (2006) innovative approach, Hillman et al. (2012) developed two new sub-categories of illustrators: speech-prompting illustrators and rhythmicpulsing illustrators. Liars made more speech-prompting illustrators, supporting the hypothesis that these illustrators may help to access the mental lexicon (Krauss, 1998; Rauscher, Krauss, \& Chen, 1996), as well as aid in the conceptual planning of the utterances (Alibali, Kita, \& Young, 2000) when the speech becomes more challenging (Feyereisen, 1983; GoldinMeadow, 2006; McNeill, 1992). Contrastingly, truth tellers made more rhythmic-pulsing illustrators, supporting the hypothesis that these illustrators were associated with the prosodic features of speech (Rauscher et al., 1996), and that truth tellers make less effort to inhibit them, in comparison with liars.

The results from these two studies "go some way to explain the rather tenuous link between deception and illustrators found by DePaulo et al. (2003) and Vrij (2008)" (Hillman et al., 2012, p. 343). These findings also revealed that the multi-factor model (Zuckerman et al., 1981) may be insufficient to explain the variations in illustrators, since it simply predicted that the increase in the cognitive load and the attempted behaviour control factors led to a decrease in illustrators. Hence, the difference between truth tellers and liars may not be related to the frequency of illustrators, but, rather, to the quality of those illustrators (Cohen, Beattie, \& Shovelton, 2010). This may also clarify the results found in the three categories of illustrators in the current study, including the slight increase of bilateral illustrators during deception. Nevertheless, both Caso et al. (2006) and Hillman et al. (2012) studies examined lies about past events, but it 
may be of consequence to determine whether their categories of illustrators yield the same results for lies about intentions.

So far, the focus has mostly been on the intrapersonal functions of illustrators (i.e., the functions they serve for the speaker). Yet, other authors claim that illustrators also carry interpersonal functions (e.g., Bavelas, Chovil, Lawrie, \& Wade, 1992; Graham \& Argyle, 1975; Kendon, 1980, 1994; McNeil, 1992; Riseborough, 1981; Rogers, 1978; Schegloff, 1984). These functions involve the inferences made by the receiver about the sender's illustrators, independently of the sender's awareness of what $\mathrm{s} / \mathrm{he}$ was displaying (Krauss et al., 1996). According to interpersonal deception theory (Buller \& Burgoon, 1996), liars and truth tellers continuously influence each other by using different impression management strategies.

One strategy is the chameleon effect (Chartrand \& Bargh, 1999), which refers to the involuntary mimicry of non-verbal behaviours during an interaction. Mimicry helps to facilitate the flow of the interaction and increases the empathetic communication between interlocutors. The interviewer from the current study naturally displayed illustrators when asking the questions. She was not requested to control her movements as that could have generated cognitive load and influenced her relationship with the interviewees. Therefore, we chose not to take into consideration her movements, even though we were aware that the frequency and type of illustrators displayed by the interviewer may have influenced the frequency and type of illustrators displayed by the participants.

\section{Hypothesis 2: Liars will make fewer subtle hand and finger movements than truth tellers}

The empirical findings supported hypothesis 2. Although the results were not statistically significant, there was a tendency for liars to demonstrate fewer subtle hand and finger movements, when compared to the truth tellers. Indeed, subtle hand and finger movements are considered "one of the most consistent cues to deceit" (Vrij et al., 2008b, p. 259). The findings were in line with DePaulo et al. (2003) and
Vrij's (2008) meta-analyses, as well as the cognitive load factor (Zuckerman et al., 1981). Investigations of police interviews with real-life suspects, which are cognitively challenging, also revealed that lies were complemented by a decrease in subtle hand and finger movements (Mann, Vrij, \& Bull, 2002; Vrij \& Mann, 2003).

Using this line of thinking, one factor that may have contributed to the decrease in subtle hand and finger movements was the 'unanticipated questions' technique (Vrij \& Granhag, 2012; Vrij et al., 2009b), which is one way of imposing an increased cognitive load. Apart from the first two questions, which were expected, all the other questions were unexpected. This means that liars had an additional cognitive challenge, as they had to answer taxing questions about the mental images of the core event, the travel details, and the planning of intentions. This extra-cognitive load may have enhanced the differences between the truth tellers and the liars (Vrij, 2015). The reduction in subtle hand and finger movements was also supported by the attempted behaviour control factor (Zuckerman et al., 1981). According to Vrij (1995, p. 17), "if [...] liars indeed behave deliberately, it is likely that they will especially avoid non-functional movements, such as subtle hand and finger movements".

No hypothesis could be suggested regarding the impact of the chameleon effect (Chartrand \& Bargh, 1999) on subtle hand and finger movements. The interviewer most likely exhibited illustrators when asking the questions, since these movements aid the production of speech (Krauss, 1998). However, subtle hand and finger movements do not appear to be associated with speech. Hence, there is no theoretical background to presuppose that the interviewer displayed subtle movements or not, or that these movements would have had any influence on the behaviour of the interviewees. Future studies could perhaps address the impact of the interviewer's subtle hand and finger movements on the behaviour of the interviewees. 


\section{Hypothesis 3: There will be no significant difference in self-adaptors between liars and truth tellers}

Hypothesis 3 was supported as the five categories of self-adaptors revealed minor differences between liars and truth tellers. These results are in line with previous empirical research, particularly with DePaulo et al. (2003) and Vrij's (2008) meta-analyses, which suggested that self-adaptors were not associated with deception. The extremely low frequency of self-adaptors may, however, be related to the experimental setting. The multi-factor approach (Zuckerman et al., 1981) predicted that when the emotional arousal increased, the self-adaptors also increased. Nonetheless, the emotional factor is typically reduced in laboratory-based studies, because participants tell low-stake lies. Guilt may have been absent given that lying was authorised, condoned and would not harm anyone (Vrij, 2008). Likewise, fear of getting caught may have been reduced or even absent as the stakes were low (Ekman, 1985, 1989; Malone \& DePaulo, 2001; Miller \& Stiff, 1993). Although liars were specifically instructed to fool the interviewer, there were no negative consequences if they got caught, or positive consequences if they succeeded, and this may explain the low frequency of self-adaptors. Nevertheless, lies told in a laboratory-based setting may be comparable with real lies told in daily life, since the majority of these are also low-stakes lies (DePaulo, Kashy, Kirkendol, Wyer, \& Epstein, 1996).

Finally, several studies proposed that self-adaptors may have a positive interpersonal function, in contrast with the theory that they serve to relieve stress and emotional arousal through sensory stimulation. For instance, Harrigan and colleagues (Harrigan, Kues, \& Weber, 1986; Harrigan, Weber, \& Kues, 1986; Harrigan, Kues, Steffen, \& Rosenthal, 1987) found that people who exhibited self-adaptors were regarded as more pleasant, honest and easier to work with, compared to those who did not display self-adaptors. These results, by suggesting that self-adaptors serve positive relational functions, may clarify why they do not appear to be linked to deception.

\section{Limitations and strengths}

The current study evidenced some limitations. The first limitation was the use of a laboratory-based setting (Warmelink et al., 2013). Although the truth tellers described their own intentions, they were in a place that was unrelated to their intentions, and the described intentions were expected to occur only a few months later. The second limitation was the small size of the sample $(N=23)$. Although not uncommon in contemporary deception research (e.g., Blair, Levine, \& Shaw, 2010; Evans, Michael, Meissner, \& Brandon, 2013; Fenn, McGuire, Langben, \& Blandón-Gitlin, 2015; Leal, Vrij, Mann, \& Fisher, 2010), it limits the generalisation of the results.

Anyway, two meta-analyses (Hartwig \& Bond, 2011, 2014) shed new light onto this matter. Their empirical findings suggest that lie detection was not significantly influenced by the number of participants (Hartwig $\&$ Bond, 2011) nor by the degree of motivation (Hartwig \& Bond, 2014). Moreover, the comparison between laboratory-based settings and field studies may have less of an influence on deceptive behaviour than was once thought (Hartwig \& Bond, 2014; for a critical review, see Buckley, 2012).

Another limitation regards the fact that the frequency and type of movements displayed by the interviewer was not addressed and may have influenced the frequency and type of movements displayed by the participants. Involuntary mimicry of non-verbal movements is usually present during interactions (Chartrand \& Bargh, 1999). Also, the study examined the interpersonal differences between different participants, instead of the intrapersonal differences. Variations in hand movements for the same participant in both conditions (truth tellers and liars) were not taken into account.

Finally, the participants were not randomly assigned to the experimental conditions. Random selection was not possible because allocation to a particular group was contingent on the participants' intentions to 
travel, which was a factor that could not be controlled (Warmelink et al., 2013). These limitations posed issues of external validity, as the current study may not be generalised or reflect a real-life scenario, especially within the legal system.

The current study has also some relevant strengths. The first one was the choice of a new research area without theoretical or empirical support, apart from one single unpublished study (Warmelink, 2012). Secondly, there was a successful adaptation of an experimental design to include the study of hand movements (Warmelink et al., 2013). This framework may be employed in forthcoming studies to examine non-verbal deception in respect of both past and future events. The third strength relates to the adoption of the 'imposing cognitive load' approach (Vrij, Fisher, Mann, \& Leal, 2006, 2008, 2009) and the 'unanticipated questions' technique (Vrij \& Granhag, 2012; Vrij et al., 2009b), which are rarely used in non-verbal deception research. Future studies could use these methods, especially in laboratory-based settings where the stakes are usually low, to enhance the behavioural differences between liars and truth tellers. A fourth strength is the selection of a heterogeneous sample in terms of age and professional activity. Participants were not typical college students (Vrij, 2008), as their ages ranged from 25 to 55 , and they were from a wide variety of professional activities (e.g., Architecture, Law, Insurance, Finance). Since this sample is more representative of the general population, this factor increased the validity of the study.

A fifth strength concerned the selection of specific subtypes of hand movements (laterality of illustrators, and laterality and length of self-adaptors) that have not been investigated in contemporary deception research. Future research could examine the impact of the laterality of illustrators in deception about past and future events. Finally, the frequency of all the participants' observable hand movements during the entire interview were scored. Several studies use a 1-7 scale, with higher scores indicating that the behaviour occurred more frequently (e.g., Warmelink, 2012), though this is a rather subjective method. Overall, the approach for the current study allowed access to a larger amount of data, collected and analysed in a reliable way.

\section{Future legal considerations}

There are several societal issues that need to be considered, namely the practical consequences of this research findings for security, justice and freedom on a global level. The main issue concerns the penalisation of an action that has not actually been executed. This is problematic, since an intention does not necessarily imply an action. Intentions are elusive due to an obvious gap between thought and action (Orbell \& Sheeran, 1998). Indeed, approximately only half of all people successfully convert their intentions into actions (Sheeran, 2002). As Anderton, the creator of the "Precrime Police Unit" in Dick's (1956, p. 2-3) story, ironically says:

\section{"You've probably already grasped the basic legalistic drawback to precrime methodology. We're taking in in- dividuals who have broken no law. [...] So the commission of the crime itself is absolute metaphysics. We can claim they are culpable. They, on the other hand, can eternally claim they're innocent. And, in a sense, they are innocent." (emphasis in original)}

For these reasons, two of the main pillars of the legal system are the presumption of innocence and the exhibition of valid criminal evidence (McCulloch \& Pickering, 2010). The freedom of thought is regarded as a primordial right (Bury, 1913), and is included in the Universal Declaration of Human Rights (UDHR drafting committee, 1948). However, the concept of precrime is no longer a science fiction expression, but a contemporary concept with real implications.

The first book devoted to this concept was published by McCulloch and Wilson (2016). According to the authors, with an ever-increasing political, ideological and social tension, especially after the $9 / 11$ incident, crime prevention may be a disguised concept for the practical application of precrime. By pursuing expected crimes as if they had already occurred, precrime alters the relationship between crime and punishment, with global repercussions for security, justice and society. 
More specifically, it creates a shift from the presumption of innocence to coercive suspicion without the need for tangible evidence. This situation was poignantly depicted in Dick's (1956, p. 3) story, when Anderton declared that "In our society we have no major crimes, [...] but we do have a detention camp full of would-be criminals".

Even though this scenario appears to be appalling, two reasons could still be provided to support the relevance of the current study and the general field of psycho-legal research on intentionality. The first reason concerns the function of the deception detection techniques. Instead of utilising them for providing evidence in court, they could be employed as support tools to guide the police during the initial screening phase of a criminal investigation (Granhag \& Mac Giolla, 2014). The second reason concerns the fact that, irrespective of the advances of research in this area, professionals need to make evaluations about people's intentions on a daily basis. Without scientific support, a significant amount of judgements of intent will remain prejudiced and based on faulty assumptions (Mac Giolla, 2016). For these reasons, solid scientific research should endure, for "even slight improvements of practitioner's classification rates could have tremendous positive effects" (Mac Giolla, Granhag, \& Vrij, 2015, p. 169).

\section{Conclusion and Future Directions}

The current study was the second experimental research carried out into non-verbal behaviours and false intentions using a psycho-legal framework. It was also the first study in this area to examine hand movements and false intentions using a specific design (Warmelink et al., 2013), a subtype of variables (Friesen et al., 1979) and a coding system (Ekman \& Friesen, 1972, 1974; Friesen \& Ekman, 1973). It should be pointed out that there is no explicit theoretical or empirical support for the assessment of the link between false verbalised intentions and non-verbal behaviour. Warmelink's (2012, p. 62-63) pioneering study concluded by declaring that "analysing someone's non-verbal behaviour with these cues [including hand movements] is not very effective at detecting deception". Nonetheless, because Warmelink's (2012) study was the only one in this new research area, additional data were necessary.

Out results may be directly comparable to the findings on deception about past events. Apart from the slight increase of bilateral illustrators during deception, all the results are in concordance with the main metaanalyses on deception research about past events (DePaulo et al., 2003; Vrij, 2008). This similarity is significant, considering the cognitive differences between lies about the past and lies about future events ( $D^{\prime}$ Argembeau \& Van der Linden, 2004; Gamboz, Brandimonte, \& De Vito, 2010).

\section{Future directions}

The promising results on subtle hand and finger movements and illustrators encourage further research into these two categories. In terms of design, forthcoming studies on false intentions could address the main limitations of the current study by using a real-life setting (Vrij et al., 2011a), a larger and randomised sample (Warmelink, 2012), and a monetary incentive (Vrij et al., 2000; Vrij, Edward, \& Bull, 2001). Another important element which could be included in prospective studies is the use of the same participants for both conditions (truth tellers and liars), in order not only to examine the interpersonal differences between participants, but also the intrapersonal differences (e.g., Caso et al., 2006). With this framework in mind, three future directions are proposed.

The first wave of research on false intentions found that the accuracy rate for lies about future events was significantly higher than the accuracy rate for lies about past events (for a review, see Granhag \& Mac Giolla, 2014). Following these results, one possible direction would be to extend Vrij's (1994) study on subtle hand and finger movements. The author found that by instructing participants to focus their attention only on these types of hand movements, the accuracy rate for lies about past events significantly improved. It would also be valuable to verify the accuracy rate on veracity judgments about intentions, while focusing solely on subtle hand and finger movements. 
A further direction would be to extend the innovative research on specific types of illustrators from Caso et al. (2006) and Hillman et al. (2012) to research into genuine and false verbalized intentions. It would be appropriate to analyse whether the deictic and metaphoric illustrators (Caso et al., 2006), and the speechprompting and rhythmic-pulsing illustrators (Hillman et al., 2012) yield the same results for deception about future events.

Finally, Caso et al. (2006) study did not consider the relationship between the illustrators and the speech content, and Hillman et al. (2012) study based their analysis of the relationship between illustrators and the speech content on a single question. Therefore, a third direction would be the adoption of a multiple cue approach (e.g., Vrij \& Mann, 2004) that would allow researchers to examine the relation between the illustrators from the two mentioned studies and the verbal cues (e.g., spatial and temporal details) found by the third wave of studies (Granhag \& Mac Giolla, 2014), at the point when anticipated and unanticipated questions are being used (see, e.g., Warmelink et al., 2013).

To conclude, the empirical findings provided by this study and the future directions encourage the development of new studies. Although it is doubtful that there will ever be clear-cut diagnostic tools, prospective research on hand movements could contribute in the long run to a better assessment of true and false verbalized intentions in a legal setting.

\section{Declaration of Conflicting Interests}

The present research was carried out as part of a master's degree in Communication, Behaviour and Credibility Analysis at Manchester Metropolitan University, UK. The author declares no conflicts of interest with respect to the research, authorship, and/or publication of this article.

\section{Acknowledgments}

This research project was supervised by Professor Dawn Archer from the Department of Languages, Information and Communications.

\section{References}

Alibali, M. W., Kita, S., \& Young, A. J. (2000). Gesture and the process of speech production: We think, therefore we gesture. Language and Cognitive Processes, 15(6), 593-613. doi: 10.1080/016909600750040571

Bavelas, J. B., Chovil, N., Lawrie, D. A., \& Wade, A. (1992). Interactive gestures. Discourse Processes, 15(4), 469-489. doi: 10.1080/01638539209544823

Blair, J. P., Levine, T. R., \& Shaw, A. S. (2010). Content in context improves deception detection accuracy. Human Communication Research, 36, 423-442. doi: 10.1111/j.14682958.2010.01382.x

Buckley, J. P. (2012). Detection of deception researchers need to collaborate with experienced practitioners. Journal of Applied Research in Memory and Cognition, 1, 126-127. doi: 10.1016/j.jarmac.2012.04.002

Buller, D. B., \& Burgoon, J. K. (1996). Interpersonal deception theory. Communication Theory, 6(3), 203-242. doi: 10.1111/j.1468-2885.1996.tb00127.x

Bury, J. B. (1913). A history of freedom of thought: The power of imagination. North Charleston, SC: Createspace Independent Publishing Platform.

Caso, L., Maricchiolo, F., Bonaiuto, M., Vrij, A., \& Mann, S. (2006). The impact of deception and suspicion on different hand movements. Journal of Nonverbal Behaviour, 30(6), 119. doi: 10.1007/s10919-005-0001-z

Chartrand, T. L., \& Bargh, J. A. (1999). The chameleon effect: The perception behavior link and social interaction. Journal of Personality and Social Psychology, 76(6), 893-910. doi: 10.1037/0022-3514.76.6.893

Cochet, H., \& Byrne, R. W. (2013). Evolutionary origins of human handedness: Evaluating contrasting hypotheses. Animal Cognition, 16(4), 531-542. doi: 10.1007/s10071-013-0626-y

Cohen, D., Beattie, G., \& Shovelton, H. (2010). Nonverbal indicators of deception: How iconic gestures reveal thoughts that cannot be suppressed. Semiotica, 182(1/4), 133-174. doi 10.1515/semi.2010.055

D' Argembeau, A., \& Van der Linden, M. (2004). Phenomenal characteristics associated with projecting oneself back into the past and forward into the future: Influence of valence and temporal distance. Consciousness and Cognition, 13(4), 84458. doi: 10.1016/j.concog.2004.07.007

DePaulo, B. M., Kashy, D. A., Kirkendol, S. E., Wyer, M. M., \& Epstein, J. A. (1996). Lying in everyday life. Journal of Personality and Social Psychology, 70(5), 979-995. doi: 10.1037/0022-3514.70.5.979 
DePaulo, B. M., Lindsay, J. L., Malone, B. E., Muhlenbruck, L., Charlton, K., \& Cooper, H. (2003). Cues to deception. Psychological Bulletin, 129(1), 74-118. doi: 10.1037/00332909.129.1.74

Dick, P. K. (1956). The minority report. London: Gollancz.

Ekman, P. (1977). Biological and cultural contributions to body and facial movement. In J. Blacking (Ed.), The anthropology of the body (pp. 39-84). London: Academic Press.

Ekman, P. (1985). Telling lies: Clues to deceit in the marketplace, politics and marriage. New York: W. W. Norton (Reprinted in 1992 and 2001).

Ekman, P. (1989). Why lies fail and what behaviors betray a lie. In J. C. Yuille (Ed.), Credibility assessment (pp. 71-82). Dordrecht, the Netherlands: Kluwer.

Ekman, P. (2003). Darwin, deception, and facial expression. Annals of the New York Academy of Science, 1000, 205-221. doi: 10.1196/annals.1280.010

Ekman, P., \& Friesen, W. V. (1969a). The repertoire of nonverbal behavior: Categories, origins, usage, and coding. Semiotica, 1, 49-98. doi: 10.1515/semi.1969.1.1.49

Ekman, P., \& Friesen, W. V. (1969b). Nonverbal leakage and clues to deception. Psychiatry, 32(1), 88-106. doi: 10.1080/00332747.1969.11023575

Ekman, P., \& Friesen, W. V. (1972). Hand movements. Journal of Communication, 22(4), 353-374. doi: 10.1111/j.14602466.1972.tb00163.x

Ekman, P., \& Friesen, W. V. (1974). Nonverbal behavior and psychopathology. In R. J. Friedman \& M. M. Katz (Eds.), The psychology of depression: Contemporary theory and research (pp. 203-232). Washington D.C.: J. Winston \& Sons.

Evans, J. R., Michael, S. W., Meissner, C. A., \& Brandon, S. E. (2013). Validating a new assessment method for deception detection: Introducing a psychologically based credibility assessment tool. Journal of Applied Research in Memory and Cognition, 2, 33-41. doi: 10.1016/j.jarmac.2013.02.002

Fenn, E., McGuire, M., Langben, S., \& Blandón-Gitlin, I. (2015). $A$ reverse order interview does not aid deception detection regarding intentions. Frontiers in Psychology, 6(1298), 1-12. doi: $10.3389 /$ fpsyg.2015.01298

Feyereisen, P. (1983). Manual activity during speaking in aphasic subjects. International Journal of Psychology, 18, 545-556. doi:10.1080/00207598308247500

Foundas, A. L., Macauley, B. L., Raymer, A. M., Maher, L. M., Heilman, K. M., \& Rothi, L. J. (1995). Gesture laterality in aphasic and apraxic stroke patients. Brain and Cognition, 29(2), 204-213. doi: 10.1006/brcg.1995.1277

Frank, M. G., \& Ekman, P. (1993). Not all smiles are created equal: The differences between enjoyment and nonenjoyment smiles. Humor, 6(1), 9-26. doi: 10.1515/humr.1993.6.1.9

Freedman, N., Blass, T., Rifkin, A., \& Quitkin, F. (1973). Body movements and the verbal encoding of aggressive affect. Journal of Personality and Social Psychology, 26, 72-85. doi: 10.1037/h0034220

Friesen, W. V., \& Ekman, P. (1973). Classification of hand activity. Unpublished manuscript.

Friesen, W. V., Ekman, P., \& Wallbott, H. (1979). Measuring hand movements. Journal of Nonverbal Behavior, 4(2), 97112. doi: $10.1007 / B F 01006354$

Gamboz, N., Brandimonte, M. A., \& De Vito, S. (2010). The role of past in the simulation of autobiographical future episodes.
Experimental Psychology, 57(6), 419-428. doi: 10.1027/16183169/a000052.

Goldin-Meadow, S. (2006). Nonverbal communication: The hand's role in talking and thinking. In W. Damon, R. M. Lerner, D. Kuhn \& R. S. Siegler (Eds.), Handbook of child psychology, volume 2: Cognition, perception and language, $6^{\text {th }}$ edition (pp. 336-369). Chichester: John Wiley and Sons.

Graham, J. A., \& Argyle, M. (1975). A cross-cultural study of the communication of extra-verbal meaning by gestures. International Journal of Psychology, 10(1), 57-67. doi: 10.1080/00207597508247319

Granhag, P. A. (2010). On the psycho-legal study of true and false intentions: Dangerous waters and some stepping stones. The Open Criminology Journal, 3(2), 37-43. doi: 10.2174/1874917801003020037

Granhag, P. A., \& Mac Giolla, E. (2014). Preventing future crimes: Identifying markers of true and false intent. European Psychologist, 19(3), 195-206. doi: 10.1027/10169040/a000202

Harrigan, J. A., Kues, J. R., Steffen, J. J., \& Rosenthal, R. (1987). Self-touching and impressions of others. Personality and Social Psychology Bulletin, 13, 497-512.

Harrigan, J. A., Kues, J. R., \& Weber, J. G. (1986). Impressions of hand movements: Self-touching and gestures. Perceptual and Motor Skills, 63, 503-16.

Harrigan, J. A., Weber, J. G., \& Kues, J. R. (1986). Attributions of self-touching performed in spontaneous and posed modes. Journal of Clinical and Social Psychology, 4, 433-446.

Hartwig, M., \& Bond, C. F. (2011). Why do lie-catchers fail? A lens model meta-analysis of human lie judgments. Psychological Bulletin, 137, 643-659. doi: 10.1037/a0023589.

Hartwig, M., \& Bond, C. F. (2014). Lie detection from multiple cues: A meta-analysis. Applied Cognitive Psychology, 28, 661676. doi: 10.1002/acp.3052

Hillman, J., Vrij, A., \& Mann, S. (2012). Um ... they were wearing ...: The effect of deception on specific hand gestures. Legal and Criminological Psychology, 17(2), 336-345. doi: 10.1111/j.2044-8333.2011.02014.x

Jupe, L. M., Leal, S., Vrij, A., \& Nahari, G. (2017). Applying the verifiability approach in an international airport setting. Psychology, Crime \& Law, 23(8), 812-825 doi: 10.1080/10683 16X.2017.1327584

Kendon, A. (1980). Gesticulation and speech: Two aspects of the process of utterance. In M. R. Key (Ed.), Relationship of verbal and nonverbal communication (pp. 207-28). The Hague: Mouton.

Kendon, A. (1994). Do gestures communicate? A review. Research on Language and Social Interaction, 27(3), 175-200. doi: 10.1207/s15327973rlsi2703_2

Krauss, R. M. (1998). Why do we gesture when we speak? Current Directions in Psychological Science, 7(2), 54-60. doi:10.111/1467-8721.ep13175642

Krauss, R. M., Chen, Y., \& Chawla, P. (1996). Nonverbal behavior and nonverbal communication: What do conversational hand gestures tell us? In M. Zanna (Ed.), Advances in experimental social psychology (pp. 389-450). San Diego, CA: Academic Press.

Leal, S., Vrij, A., Mann, S., \& Fisher, R. P. (2010). Detecting true and false opinions: The devil's advocate approach has a lie detection aid. Acta Psychologica, 134, 323-329. doi: 10.1016/j.actpsy.2010.03.005 
Mac Giolla, E. (2016). Towards a theory of true and false intentions. (Doctoral thesis, Department of Psychology, University of Gothenburg, Sweden), Retrieved from https://gupea.ub.gu.se/handle/2077/43237

Mac Giolla, E., Granhag, P. A., \& Vrij, A. (2015). Discriminating between true and false intentions. In P. A. Granhag, A. Vrij \& B. Verschuere (Eds.), Detecting deception: Current challenges and cognitive approaches (pp. 155-173). Chichester: John Wiley \& Sons.

Mäki-Marttunen, V., Villarreal, M., \& Leiguarda, R. C. (2014). Lateralization of brain activity during motor planning of proximal and distal gestures. Behavioural Brain Research, 272, 226-237. doi: 10.1016/j.bbr.2014.06.055

Malone, B. E., \& DePaulo, B. M. (2001). Measuring sensitivity to deception. In J. A. Hall \& F. J. Bernieri (Eds.), Interpersonal sensitivity: Theory and measurement (pp. 103-124). Mahwah, NJ: Erlbaum.

Mann, S., Vrij, A., \& Bull, R. (2002). Suspects, lies and videotape: An analysis of authentic high-stakes liars. Law and Human Behavior, 26(3), 365-376. doi: 10.1023/A:1015332606792

Mann, S., Vrij, A., Leal, S., Granhag, P. A., Warmelink, L., \& Forrester, D. (2012). Windows to the soul? Deliberate eye contact as a cue to deceit. Journal of Nonverbal Behavior, 36,(3), 205-215. doi: 10.1007/s10919-012-0132-y

Mann, S., Vrij, A., Nasholm, E., Warmelink, L., Leal, S., \& Forrester, D. (2012). The direction of deception: Neurolinguistic programming as a lie detection tool. Journal of Police and Criminal Psychology, 27(2), 160-166. doi: 10.1007/s11896011-9097-8

McCulloch, J., \& Pickering, S. (2010). Future threat: Pre-crime, state terror, and dystopia in the $21^{\text {st }}$ century. Criminal Justice Matters, 81(1), 32-33. doi: 10.1080/09627251 .2010.505400

McCulloch, J., \& Wilson, D. (2016). Pre-crime: Pre-emption, precaution and the future. London: Routledge.

McNeill, D. (1992). Hand and mind: What gestures reveal about thought. Chicago: University of Chicago Press.

Miller, G. R., \& Stiff, J. B. (1993). Deceptive communication. Newbury Park, CA: Sage.

Mintzlaff, V., Carney, D., \& Harrigan, J. A. (1999). The link between defensiveness and nonverbal behavior: The hands have $i t$. Paper presented at the meeting of the American Psychological Society, Denver, CO.

Mumford, K. H., \& Kita, S. (2016). At 10-12 months, pointing gesture handedness predicts the size of receptive vocabularies. Infancy, 21(6), 751-765. doi: 10.1111/infa.12138

Myers, A., \& Hansen, C. (2012). Experimental psychology, $7^{\text {th }}$ edition. Belmont, CA: Wadsworth Cengage Learning.

Orbell, S., \& Sheeran, P. (1998) 'Inclined abstainers': A problem for predicting health-related behaviour. British Journal of Social Psychology, 37(2), 151-166. doi: 10.1111/j.20448309.1998.tb01162.x

Rauscher, F. H., Krauss, R. M., \& Chen, Y. (1996). Gesture, speech and lexical access: The role of lexical movements in speech production. Psychological Science, 7(4), 226-231. doi: 10.111/j.1467-9280.1996.tb00364.x

Rogers, W. T. (1978). The contribution of kinesic illustrators toward the comprehension of verbal behaviors within utterances. Human Communication Research, 5(1), 54-62. doi: 10.1111/j.1468-2958.1978.tb00622.x

Riseborough, M. G. (1981). Physiographic gestures as decoding facilitators: Three experiments exploring a neglected facet of communication. Journal of Nonverbal Behavior, 5(3), 172183. doi: $10.1007 / B F 00986134$

Schacter, D. L., \& Addis, R. D. (2007). The cognitive neuroscience of constructive memory: Remembering the past and imaging the future. Philosophical Transactions of the Royal Society, 362, 773-786. doi: 10.1098/rstb.2007.2087

Schacter, D. L., Addis, D. R., \& Buckner, R. L. (2008). Episodic simulation of future events: Concepts, data and applications. Annals of New York Academy of Sciences, 1124(1), 39-60. doi: 10.1196/annals.1440.001

Schegloff, E. (1984). On some gestures' relation to talk. In J. M. Atkinson \& J. Heritage (Eds.), Structures of social action (pp. 266-295). Cambridge: Cambridge University Press.

Sheeran, P. (2002). Intention-behavior relations: A conceptual and empirical review. European Review of Social Psychology, 12, 1-36. doi: 10.1080/14792772143000003

Szpunar, K. K. (2010). Episodic future thought: An emerging concept. Perspectives on Psychological Science, 5(2), 142162. doi: $10.1177 / 1745691610362350$

UDHR drafting committee (1948). Universal Declaration of Human Rights. Retrieved from: http://www.un.org/en/ universal-declaration-human-rights/index.html

Vrij, A. (1993). Credibility judgments of detectives: The impact of nonverbal behavior, social skills and physical characteristics on impression formation. Journal of Social Psychology, 133(5), 601-611. doi: 10.1080/00224545.1993.9713915

Vrij, A. (1994). The impact of information and setting on detection of deception by police detectives. Journal of Nonverbal Behavior, 18(2), 117-137. doi: 10.1007/BF0 2170074

Vrij, A. (1995). Behavioral correlates of deception in a simulated police interview. Journal of Psychology: Interdisciplinary and Applied, 129(1), 15-29. doi: 10.1080/00223980.1995.991 4944

Vrij, A. (2008). Detecting lies and deceit: Pitfalls and opportunities, $2^{\text {nd }}$ edition. Chichester: John Wiley \& Sons.

Vrij, A. (2014). Interviewing to detect deception. European Psychologist, 19 (3): 184-194. doi: 10.1027/1016-9040/a000201.

Vrij, A. (2015). A cognitive approach to lie detection. In P. A. Granhag, A. Vrij \& B. Verschuere (Eds.), Detecting deception: Current challenges and cognitive approaches (pp. 205-229). Chichester: John Wiley.

Vrij, A., Akehurst, L., \& Morris, P. M. (1997). Individual differences in hand movements during deception. Journal of Nonverbal Behavior, 21(2), 87-102. doi: 10.1023/A:1024951902752

Vrij, A., Edward, K., \& Bull, R. (2001). Stereotypical verbal and nonverbal responses while deceiving others. Personality and Social Psychology Bulletin, 27(7), 899-909. doi: 10.1177/0146167201277012

Vrij, A., Edward, K., Roberts, K. P., \& Bull, R. (2000). Detecting deceit via analysis of verbal and nonverbal behavior. Journal of Nonverbal Behavior, 24(4), 239-263. doi: 10.1023/A:1006610329284

Vrij, A., Fisher, R. P., Mann, S., \& Leal, S. (2006). Detecting deception by manipulating cognitive load. Trends in Cognitive Sciences, 10(4), 141-142. doi: 10.1016/j.tics.2006.02.003

Vrij, A., Fisher, R. P., Mann, S., \& Leal, S. (2008). A cognitive load approach to lie detection. Journal of Investigative Psychology and Offender Profiling, 5(1-2), 39-43. doi: 10.1002/jip.82

Vrij, A., Fisher, R., Mann, S., \& Leal, S. (2009). Increasing cognitive load in interviews to detect deceit. In B. Milne, S. Savage 
\& T. Williamson (Eds.), International developments in investigative interviewing (pp. 176-189). Uffculme: Willan Publishing.

Vrij, A., \& Granhag, P. A. (2012). Eliciting cues to deception and truth: What matters are the questions asked. Journal of $A p$ plied Research in Memory and Cognition, 1(2), 110-117. doi: 10.1016/j.jarmac.2012.02.004

Vrij, A., Granhag, P. A., Mann, S., \& Leal, S. (2011a). Lying about flying: The first experiment to detect false intent. Psychology, Crime \& Law, 17(7), 611-620. doi: $10.1080 / 10683160903418213$

Vrij, A., Leal, S., Granhag, P. A., Mann, S., \& Leal, S. (2011b). Outsmarting the liars: Toward a cognitive lie detection approach. Current Directions in Psychological Science, 20(1), 2832. doi: $10.1177 / 0963721410391245$

Vrij, A., Leal, S., Granhag, P. A., Mann, S., Fisher, R. P., Hillman, J., \& Sperry, K. (2009b). Outsmarting the liars: The benefit of asking unanticipated questions. Law and Human Behavior, 33(2), 159-166. doi: 10.1007/s10979-008-9143-y

Vrij, A., \& Mann, S. (2003). Deception detection. In P. W. Halligan, C. Bass \& D. A. Oakley (Eds.), Malingering and illness deception (pp. 348-362). Oxford: Oxford University Press.

Vrij, A., \& Mann, S. (2004). Detecting deception: The benefit of looking at a combination of behavioral, auditory and speech content related cues in a systematic manner. Group Decision and Negotiation, 13(1), 61-79. doi: 10.1023/B:GRUP. 0000011946.74290.bc

Vrij, A., Mann, S., Fisher, R. P., Leal, S., Milne, R., \& Bull, R. (2008b). Increasing cognitive load to facilitate lie detection:
The benefit of recalling an event in reverse order. Law and Human Behavior, 32(3), 253-265. doi: 10.1007/s10979-0079103-y

Vrij, A., Semin, G. R., \& Bull, R. (1996). Insight into behavior displayed during deception. Human Communication Research, 22(4), 544-562. doi: 10.1111/j.1468-2958.1996.tb00378.x

Warmelink, L. (2012). Lying about intentions. (Doctoral thesis, Department of Psychology, University of Portsmouth, UK), Retrieved from https://researchportal.port.ac.uk/portal/en/theses/lying-about-intentions(83f7ccc7-b603-4a6d88b7-b57ef6861cff).html

Warmelink, L., Vrij, A., Mann, S., \& Granhag, P. A. (2013). Spatial and temporal details in intentions: A cue to detecting deception. Applied Cognitive Psychology, 27(1), 101-106. doi: 10.1002/acp.2878

Warmelink, L., Vrij, A., Mann, S., Jundi, S., \& Granhag, P. A. (2012). The effect of question expectedness and experience on lying about intentions. Acta Psychologica, 141(2), 178183. doi: 10.1016/j.actpsy.2012.07.011

Warmelink, L., Vrij, A., Mann, S., Leal, S., Forrester, D., \& Fisher, R. P. (2011). Thermal imaging as a lie detection tool at airports. Law and Human Behaviour, 35(1), 40-48. doi: 10.1007/s10979-010-9251-3

Zuckerman, M., DePaulo, B. M., \& Rosenthal, R. (1981). Verbal and nonverbal communication of deception. In L. Berkowitz (Ed.), Advances in experimental social psychology, volume 14 (pp. 1-57). New York: Academic Press. doi: 10.1016/S00652601(08)60369-X 